\title{
EDUCAÇÃO EM SAÚDE BUCAL: Uma Abordagem Reflexiva em Prol da Qualidade de Vida
}

\section{Oral health education: a reflective approach to the quality of life}

\author{
Jair Antonio de Carvalho ${ }^{1}$ \\ Marcella Tamiozzo Pereira Torres ${ }^{2}$ \\ Luciana Sant'Ana de Souza ${ }^{3}$ \\ Renata da Silva de Araújo Pedrote ${ }^{4}$ \\ Fábio Aguiar Alves 5
}

\section{Resumo}

Este trabalho visa reflexão crítica, sobre as ações que determinam um bom nível de saúde bucal. A promoção da saúde é um processo que pode afetar positivamente a qualidade de vida de uma população. Os problemas dentários apresentam uma baixa prioridade frente às doenças consideradas de relevância social. A prevenção das doenças bucais deve ser desenvolvida, em três níveis: primários, secundários e terciários. $\mathrm{O}$ auto-diagnóstico é de extrema importância, pois quanto mais cedo for detectado o problema e acionados os serviços de prevenção, maiores são as possibilidades de um tratamento eficaz. Entre os problemas de saúde bucal, a cárie dentária é considerada como um dano a merecer maior prioridade por sua grande prevalência. $\mathrm{O}$ câncer bucal ganhou o segundo grau de prioridade, devido a sua gravidade, vindo a seguir as doenças periodontais. A educação em saúde bucal tem sido cada vez mais requisitada, levando-se em conta o baixo custo e as possibilidades de impacto odontológico para a saúde coletiva. Portanto, o papel de educar não deve ser atribuição exclusiva do profissional convencionalmente denominado professor, mas de qualquer cidadão.

Palavras-chave: Saúde bucal; Campanhas educativas; Qualidade de vida.

\section{Abstract}

The present study aims to develop a critical reflexion about actions that determine a good level of oral health and the need for education measures to improve the human being life quality. The health promotion in any life stage is a process that can positively affect the population's life quality. Dental problems seem to represent low social relevance. However, when the subject is oral health, the epidemiological situation in Brazil is still a big concern. Preventive measures for oral diseases should be developed in primary, secondary and tertiary levels. The auto-diagnosis of oral problems is still a concern, the earliest detected the better. The oral cancer gained a second level of priority regarding its extreme morbidity followed by periodontal diseases. The education campaign in public health has been increasingly recruited because of its low cost and possibility of impact to public health. Hitherto, the importance in education should not be given exclusively to the conventional education professional, but to any citizen in contact to human beings and environment.

Keywords: oral health, education campaign, life quality.

${ }^{1}$ Mestre - Ciências da Saúde e do Meio Ambiente - UniFOA

${ }^{2}$ Especialista - Nutrição Clínica - USC

${ }^{3}$ Especialista - ESF - UFT

${ }^{4}$ Odontóloga - FAA

${ }^{5}$ Pós graduaçấo em Patologia - Universidade Federal Fluminense e Ciências da Saúde e do Meio Ambiente - UniFOA 


\section{INTRODUÇÃO}

A promoção da saúde em qualquer etapa da vida é um processo que pode afetar positivamente a qualidade de vida de uma população. Um trabalho comunitário integrado, de políticas públicas de saúde, com atividades de todas as áreas, exerce papel importante no estabelecimento do padrão socio-econômico da comunidade.

Segundo Chaves (1986), saúde são a plenitude e harmonia das funçôes físicas, o equilíbrio dos processos mentais e o desempenho eficiente das atividades sociais. $\mathrm{O}$ mesmo autor relata ainda, que os dois primeiros aspectos (físicos e mentais), estão reconhecidamente sob a égide da medicina, enquanto que o bem estar social envolve também outras áreas, como educação, recreação, seguridade social entre outros.

Nos primórdios da humanidade os indivíduos não tinham alimentos processados, o que exigia dos mesmos, grande força muscular para realizar o processo de mastigação (MONTENEGRO 2007).

A saúde bucal é um componente essencial para o estado de saúde do indivíduo, essa conduta tem sido relegada ao esquecimento por muitas pessoas, levadas por questóes das mais diversas, desde a questão da falta de informação, passando pelo fator econômico e pelo descaso com a saúde bucal, no caso do brasileiro, quando se discutem as condiçôes de saúde da população.

Apesar de todo o desenvolvimento da odontologia em tecnologia, ela ainda não atende em níveis satisfatórios à demanda da população, por vários motivos, entre os quais os investimentos em saúde pública.

O SUS (Sistema Único de Saúde) encontra, ainda hoje, múltiplos obstáculos para sua efetividade. Encontramos "nós" na macropolítica em saúde que vão desde a falta de recursos financeiros passando pela deficiente intersetorialidade, até a carência de profissionais aptos a trabalhar com a concepção de saúde ampliada. Estas dificuldades implicam em baixa virtude de produzir efeitos nas açóes e serviços públicos de saúde (PESSANHA 2009).

Nas últimas décadas a saúde bucal não tem sido muito valorizada pelas pessoas em geral. A prevenção em odontologia no Brasil só passou a despertar interesse a partir do final da década de 70 .

Nos países em desenvolvimento como é o caso do Brasil, não há ainda uma prática definida de saúde bucal, portanto há significativas parcelas da população sem acesso a cuidados clínicos e preventivos de maneira regular.

Dados da Pesquisa Nacional por Amostragem por Domicílios, (PNAD), de 1998, realizada pelo IBGE, revelam que a saúde bucal no Brasil tem recebido uma parcela escassa de recursos em relação ao total de investimentos do SUS. Do ponto de vista do acesso aos serviços odontológicos, o SUS é um agente de grande importância, porém com um papel proporcionalmente pequeno: Em 1998, revela a pesquisa, apenas $5,24 \%$ dos investimentos em saúde se destinavam aos procedimentos odontológicos (PAULETO et al. 2004).

Rosa (1992) relata que os problemas de saúde bucal na maioria da população são relegados ao descaso no Brasil, transformando-se em fator de aceleração dos problemas naturais $\mathrm{da}$ velhice, tornando-a mais incômoda do que deveria ser.

É de extrema importância a implantação de serviços de odontologia nos locais de trabalho, especialmente nas empresas em que concentram grande número de trabalhadores, haja visto que, segundo Pinto (2000), 60\% do tempo de vida das pessoas economicamente ativas, é despendido no emprego em local de trabalho.

Em se tratando de saúde bucal, a questão epidemiológica do Brasil, ainda é grave em função da questão sócio econômica da população, os investimentos deficitários dos órgãos públicos e a falta de informação sobre os cuidados básicos de saúde.

O sucesso de um programa destinado a elevar o nível de saúde bucal, por melhor que seja o seu planejamento, por mais eficientes que sejam os métodos propostos, por mais favorável que seja o ambiente e por mais clara que seja a definição de seus objetivos, depende fundamentalmente de recursos humanos adequadamente preparados.

Quando falamos em preparação adequada, devemos ter em mente não apenas a utilizaçáo do profissional de saúde bucal para a solução de problemas imediatos, mas também a sua capacitação para sentir e gradualmente ajustar o seu comportamento às modificaçóes de natureza tecnológica, sócio-econômica e cultural, cuja interação obriga a uma constante revisão do papel a ser desempenhado pela odontologia como instituição social.

McDonald (2001) relata que a integração de atividades de saúde bucal na comunidade, exerce um papel importante no estabelecimento de coalizóes, que podem ser úteis quando a odontologia necessita de aliados para sustentar as políticas públicas de saúde ou para a criação de fundos de investimentos para as iniciativas de saúde bucal.

A educação em saúde bucal tem sido cada vez mais requisitada, levando-se em conta o baixo custo e as possibilidades de impacto odontológico para a saúde coletiva (PAULETO et al. 2003).

Neste contexto, a ênfase na incorporação das ciências da educação ao processo de formação de recursos humanos é um dos aspectos a ser considerado, não só do ponto de vista do dentista de saúde pública, mas principalmente do ponto de vista da classe odontológica como um todo, visto ser a odontologia uma profissão de caráter eminentemente social.

Acreditamos que o papel de educar não deve ser atribuição exclusiva do profissional convencionalmente deno- 
minado professor, mas de qualquer cidadão, pois a todo o momento estamos educando e sendo educados através dos nossos contactos com outros seres humanos e com o meio ambiente. $\mathrm{O}$ cirurgião-dentista não foge a esta regra, razão pela qual consideramos útil o conteúdo deste trabalho.

A educação deve visar o pleno desenvolvimento da personalidade humana e ao fortalecimento do respeito pelos direitos do homem e pelas liberdades fundamentais (CHAVES 1986).

O auto-diagnóstico dos problemas bucais é de extrema importância, uma vez que quanto mais cedo for detectado qualquer tipo de problema, uma vez acionados os serviços de prevenção primária, maiores são as possibilidades de um tratamento, mais rápido, mais econômico e com maiores possibilidades de sucesso.

Segundo Kiyak (apud Pinto 2000), aqueles que acostumaram ter mais cuidado com a aparência pessoal são os que têm maiores possibilidades de valorizar sua saúde bucal. Há necessidade de intensificar ações educativas de saúde visando instrumentalizar a população com os conhecimentos e técnicas de auto-exame; possibilitando assim que se tenha uma população com mais saúde e mais qualidade de vida.

Abegg (1997) afirma que, as práticas de higiene bucal desempenham importante papel na prevenção das doenças bucais, especialmente a doença periodontal.

Tem como objetivo oportunizar uma reflexão sobre as açôes que determinam um bom nível de saúde bucal e conseqüentemente uma melhor qualidade de vida para a população, visando desenvolver uma reflexão crítica sobre o tema; despertar para a importância da informação como meio de atingir uma boa saúde bucal; difundir medidas práticas preventivas simples que possam ser aplicadas por comunidades de baixa renda, a fim de garantir a preservação dos dentes e contribuir para a elaboração de novos programas educativos na área da odontologia.

Este trabalho se justifica, devido à importância das práticas preventivas e educativas em saúde bucal e a sua relaçáo direta com a qualidade de vida das pessoas. Portanto faz-se necessário discutir a realidade odontológica das populaçóes a fim de despertar para os cuidados com a saúde bucal desde tenra idade.

\section{DESENVOLVIMENTO}

Uma profissão deve ser avaliada pelo alcance efetivo dos objetivos para os quais foi criada, e não pelo status na sociedade e êxito financeiro de seus profissionais ou, ainda, pela beleza e imponência das sedes das entidades de representação classista.

O objetivo primordial do trabalho de um cirurgiáodentista consiste em proporcionar uma boa saúde bucal aos seus pacientes. Para a odontologia como um todo, isso corresponde ao alcance de níveis ou padróes adequados de saúde bucal para o conjunto da população de um país, de uma região ou de uma localidade. O sucesso pessoal no exercício da odontologia não é e não deve ser incompatível com o alcance desses ideais (PINTO 2000).

A promoção da saúde no seu sentido mais amplo, talvez o mais apropriado, seja uma ação global, objetivando a melhoria na qualidade de vida das pessoas. A saúde bucal é apenas uma pequena parte do todo. A promoção da saúde envolve uma mudança de paradigmas, na qual se sugere que, para uma pessoa ser saudável, a ausência de doença não é suficiente e nem tão pouco necessária. Na verdade um estado saudável não é assegurado pela ausência de doenças, podendo até mesmo ser compatível com certo número de doenças. Saúde e doença são determinadas por fatores sociais, econômicos e psicológicos.

Segundo Rocha (2008) a saúde bucal tem reconhecida importância como componente de qualidade vida de uma pessoa, porém uma parcela considerável da população brasileira não tem acesso às açóes e aos serviços odontológicos.

Tanto no Brasil como nos países mais desenvolvidos, os progressos tecnológicos e os avanços dos estudos no campo da saúde levam a um aumento na expectativa de vida do homem. Segundo Colussi (2002), o decréscimo das taxas de mortalidade, associado à melhoria nas condiçóes de saneamento básico, também são fatores que resultam numa participação cada vez mais significativa das populaçóes. A prática odontológica, fundamentada em um modelo, que com freqüência termina por concentrar sua oferta de serviços a grupos de média e alta renda, daí resultando no estreitamento do alcance dos avanços tecnológicos que terminam por beneficiar apenas os setores economicamente mais favorecidos da população.

As crises econômicas, os desajustes sociais e uma inadequação do sistema de atençáo clínica e preventiva à população figuram entre as mais notórias razóes que explicam os contrastes observados na realidade brasileira, além do limitado acesso da população aos serviços que atuam nessa área.

Para Pinto (2000) os problemas dentários apresentam uma baixa prioridade, frente às doenças consideradas de relevância social. Entre os problemas de saúde bucal (sem comparação com os danos à saúde em geral), a cárie dentária é considerada como dano a merecer maior prioridade por sua prevalência combinada com o conhecimento que as pessoas têm a seu respeito e que as levam a procurar atendimento. $\mathrm{O}$ câncer bucal ganhou o segundo grau de prioridade, devido a sua extrema gravidade. É importante lembrar que a escala pode variar de acordo com a comunidade ou agrupamento de indivíduos, devendo ser traçada de acordo com cada grupo social. Adultos, em especial os de meia idade e idosos, enfrentam o ataque preponderantemente das 
doenças periodontais. A ordem de apresentação dos danos bucais neste trabalho, foi aleatória, não seguindo nenhuma escala de prioridades.

A prevenção das doenças bucais deve ser desenvolvida em três níveis:

- Primário - quando a doença se apresenta em fase inicial.

- Secundário - quando se trata de impedir a propagação da doença e sua recorrência.

- Terciário - quando se trabalha no sentido de evitar a perda da função.

A educação e a informação sobre a saúde bucal vêem sendo ressaltadas por vários pesquisadores como fatores que tem ação direta sobre a saúde de uma população, embora nos últimos anos através dos serviços do ESF (Estratégias saúde da Família) desenvolvam programas educacionais sobre a saúde bucal, sabe-se também que estes programas não chegam a todas as camadas da população.

O uso do fio dental é uma prática de higiene bucal mais recente do que a escovação acredita-se que uma grande parte da população faz uso diário deste instrumento. Segundo Abegg (1997), as mulheres usam o fio dental e praticam a escovação com maior freqüência do que os homens, na população adulta de Porto Alegre.

\section{CÁRIE}

Processo em virtude do qual se desenvolvem, nas superfícies dentárias, bactérias, que ao atuarem sobre o hidrato de carbono produzem ácidos capazes de destruir gradualmente o esmalte e a dentina. Disto pode resultar infecção local e destruição definitiva do dente atacado.

Os fatores biológicos são essenciais para o aparecimento de várias doenças na população, muitas delas com comportamento endêmico, constata-se que existem outros fatores capazes de favorecer o aparecimento e influir no ritimo de sua expansão. Para conservar os dentes sãos devem ser adotadas medidas preventivas e corretivas. A prevenção da cárie começa com a dieta. Uma dieta balanceada, que inclua carne, leite, ovos, frutas e verduras, é essencial para uma boca sadia. Deve-se limitar o uso de doces, amidos e carboidratos, como caramelos, pão e batatas que favorecem a formação de ácidos.

É importante a limpeza regular dos dentes com escova de pasta dentifrícia. O dentista poderá indicar o melhor meio de realizar esta limpeza, que será mais eficaz após as refeiçôes. A adição experimental de flúor à água, das estações fornecedoras, levou à diminuição significativa das cáries. Outro avanço foi a descoberta da relação existente entre a cárie dentária e a deficiência de vitamina C.
A cárie dentária, o câncer bucal e a doença periodontal são os males que mais acometem a cavidade bucal, sendo a cárie o mais comum em crianças. Segundo Pinto (2000) nos paises ocidentais o consumo de açúcar, favoreceu o aumento dos casos de cárie dental, especialmente em crianças e adolescentes, até atingir padróes nunca vistos.

A cárie dentária continua a ser o principal problema da odontologia e deve receber muita atenção na prática diária, não só em relação aos procedimentos restauradores, como também em termos de técnicas preventivas, adotadas para a redução do problema.

Pauleto (2004) relata que no Brasil, a prevalência da cárie dentária, por volta dos 12 anos de idade, está diminuindo desde a década de 1970, apesar de já ter sido um dos maiores problemas para a odontologia. Relata ainda que em levantamento epidemiológico realizado em 1986 em 16 cidades da área urbana, a pior situação ocorreu entre pessoas de menor renda, para o grupo na faixa etária de 6 aos 9 anos.

Estudos epidemiológicos periódicos quando realizados de forma criteriosa em qualquer nível (local, regional ou nacional) em condições homogêneas, permitem identificar a prevalência e a distribuição das doenças. Segundo Baldani et al. (2002) os levantamentos básicos devem produzir dados confiáveis, possibilitando o desenvolvimento de programas de saúde bucal e de pessoal para sua execução.

Para Schou 1993, (apud Pinto, 2000):

Numerosas justificativas podem ser arroladas em favor da implantação de serviços odontológicos para a populaçâo economicamente ativa urbana e de modo especial para o segmento dos trabalhadores:

- prevalência muito alta de problemas relacionados à cárie dental e ao periodonto;

- possibilidade de detecção precoce de lesóes relacionadas ao câncer bucal e a manifestaçôes orais de AIDS e outras doenças de relevância vital;

- cerca de 60\% do tempo de vida ativa é despendido no emprego ou local de trabalho;

- aumento das chances de desenvolver um programa participativo;

- redução potencial do absenteísmo, do número de horas perdidas na produção e dos gastos empresariais e pessoais por questôes de saúde;

- aumento da produtividade e da satisfação da força de trabalho;

- posição favorável das representaçôes sindicais e dos trabalhadores em geral, que consideram ser o ambiente de trabalho adequado para o desenvolvimento de ações de promoção da saúde. 
No tratamento da cárie a prevenção primária é entendida como sendo principalmente a fluoretação; prevenção secundária; o diagnóstico precoce e a intervenção nas lesões e na prevenção terciária, as próteses.

Embora poucas pessoas saibam que o uso do flúor seja uma medida para o controle da cárie, a utilização do flúor é reconhecidamente o método mais recomendados, quando se refere à prevenção da cárie dentária, e recomendado pelos profissionais da odontologia UNFER (2000).

No cuidado com a boca, deve tornar-se hábito a visita regular ao dentista para exame (inclusive por raios-X) limpeza e tratamento. As crianças devem ser levadas cedo ao dentista para um primeiro exame e depois a cada seis meses. O melhor meio de deter a cárie em uma cavidade e evitar a formação de outras consiste em obturaçóes, que se podem fazer à base de cimentos e amálgamas especiais e incrustaçôes ou forrações a ouro. O processo da cárie é dominado eliminando-se a parte cariada do dente e tratando-o para receber a obturação. $\mathrm{O}$ paciente deve, naturalmente, seguir todo o tratamento recomendado pelo dentista.

Medidas práticas de controle da cárie vêm sendo utilizadas pelos profissionais da área com diferentes graus de sucesso, porém somente uma medida não será inteiramente satisfatória, todas as medidas técnicas possíveis, devem ser consideradas na esperança de combater, com sucesso, a cárie dentária apontada com freqüência como a doença humana mais disseminada (McDONALD 2001).

\section{CÂNCER BUCAL}

Nos últimos anos tem-se registrado uma ascensão progressiva de mortalidade por doenças crônico degenerativas, destacando-se as neoplasias malignas, correspondendo a segunda causa morte no Brasil, quando excluídas as causas externas (SANTOS 2009).

O câncer bucal é um problema de Saúde Pública prioritário, apesar da não disponibilidade de meios adequados para sua prevenção; devido a sua letalidade. O câncer bucal inclui qualquer alteração maligna, com localização no lábio, língua, glândulas salivares, gengiva, assoalho da boca, mucosa da bochecha, vestíbulo da boca e úvula (PINTO 2000).

O câncer bucal pode ser facilmente detectado através de exames relativamente simples, e o prognóstico da doença está ligado à fase em que ela é detectada (PINHEIRO 2010).

Santos (2009) afirma ainda que, a maioria dos pacientes portadores do câncer de boca só é diagnosticado no estágio avançado da doença, talvez porque no estágio inicial a lesão maligna se apresente assintomática e com aparência inofensiva.

Segundo Carvalho (2001), o carcinoma epidermóide da cavidade oral, como outros tumores das vias aéreo di- gestivas superiores, é reconhecidamente uma neoplasia que atinge preferencialmente os pacientes do sexo masculino.

O câncer bucal é uma das doenças bucais que ocorrem com mais freqüência, depois da cárie dentária. Leite (apud Matos -2003) refere-se ao perfil predominante do portador de Câncer Bucal da seguinte forma: homens com idade entre 45 e 55 anos, etilistas e tabagistas. Uma das possíveis explicaçóes para esse perfil deve-se ao fato de que as mulheres são mais cuidadosas do que os homens com as questóes relativas aos cuidados com a saúde sobre todos os aspectos.

O câncer bucal é uma doença das mais importantes deste órgão, devido sua gravidade, reconhecida urgência de diagnóstico e susceptibilidade ao tratamento, quando tratada precocemente.

Kiyak (apud Pinto - 2000) sugere uma campanha educativa sistemática com conteúdos ligados à saúde bucal, especialmente envolvendo ensino de técnicas de autoexame para detecção precoce de sinais e sintomas ligados ao câncer bucal e outros problemas.

Pesquisas têm demonstrado que raramente o câncer bucal é diagnosticado no seu estágio inicial da doença, a grande maioria dos casos é diagnosticada nos estágios mais avançados, o que reduz a chance de sobrevida do portador. Esta doença é uma das poucas doenças deste órgão em que o dentista tem uma participação secundária, na grande maioria das vezes.

Segundo dados do (INCA) Instituto Nacional do Câncer (apud Pinto 2000), mostram que 60\% dos pacientes admitidos, chegam com câncer de boca em estágio avançado e sem chance de tratamento curativo eficaz. Pinto (2000), afirma ainda que nos últimos 10 anos o quadro não sofreu alteraçóes, evidenciando a falta de acesso aos serviços de saúde por parte das pessoas e o despreparo de alguns profissionais dentistas em detectar o câncer de boca em estágios iniciais.

Segundo Matos (2003) apesar da grande maioria dos cirurgiôes dentistas considerar-se em condiçóes de diagnosticar as lesóes cancerígenas, na realidade somente a metade costuma fazê-lo.

Segundo Pinto (2000), os fatores externos mais associados ao desenvolvimento do câncer de boca são: o fumo, o álcool e a exposição à radiaçáo solar. Entre os pacientes de diversos países, portadores de câncer bucal, 1/3 deles são fumantes. Acredita-se que $60 \%$ das substâncias contidas no tabaco e na sua fumaça apresentam ação carcinogênica.

Os tumores do assoalho bucal e língua são os que estâo mais relacionados à ingestão de álcool. $\mathrm{O}$ consumo do álcool etílico, especialmente a cachaça e o vinho de má qualidade, é maléfico à saúde bucal, tendo ação nociva especialmente no que se refere ao câncer de língua.

Pessoas que se expóem continuamente ao sol, correm o risco de apresentar o câncer de lábio inferior, especialmente 
as pessoas de pele clara, com pouca pigmentação melânica.

Uma higiene bucal não adequada representa risco adicional quanto ao aparecimento do câncer de boca.

Próteses dentárias mal-ajustadas, câmaras de sucção destinadas à maior fixação da dentadura, dentes fraturados e restos de dentes não removidos; constituem, a longo prazo, causas de lesóes devidas à irritação constante e prolongada da mucosa bucal.

As lesões da cavidade bucal ocorrem em maior incidência na língua e no assoalho, entretanto as mulheres têm uma incidência menor dessas lesóes quando comparadas aos homens CARVALHO, et al, (2001).

Apresentam risco para desenvolver o câncer bucal, as pessoas que se enquadram nos seguintes casos:

- Sexo masculino (predominante),

- Idade superior a 40 anos,

- Tabagistas crônicos,

- Etilistas crônicos,

- Com má higiene bucal,

- Desnutridos.

- Imuodeprimidos,

- Portadores de próteses mal-ajustadas,

- Portadores de irritação crônicas na mucosa bucal e

- Expostos continuamente ao sol.

\section{DISCUSSÃO}

Trabalhar com a diversidade é elemento fundamental para o crescimento, tanto do aprendiz quanto do orientador da aprendizagem, portanto, a troca é a base desta relação educacional, o que significa considerar as diferenças como algo que seja motivo de trocas, propício para o crescimento dos indivíduos envolvidos. (VAZ et al. 2005).

$\mathrm{Na}$ Conferência Municipal de Segurança Alimentar, realizada em Volta Redonda (RJ) em 2007, chegou-se à conclusão de que a falta de informação é um dos fatores, que comprometem consideravelmente a saúde de uma população.

Segundo Abreu (2006), mais importante não são as informações em si, mas o ato de transformá-las em conhecimento. As informaçóes são os tijolos e o conhecimento o edifício que construímos.

A educação é fator essencial no reconhecimento dos direitos do cidadão. Hoje a necessidade de educação permanente tornou-se parte integrante da vida. A educação continuada, pode contribuir tarefa complexa, implica em criar novos significados e sentidos para a higiene oral. Focar teoria e prática é fator primordial para que os programas de ensino em Saúde bucal alcancem os objetivos desejados.

Sugere-se que os métodos tradicionais de educação em saúde sejam substituídos por uma pedagogia participativa e de- senvolvida a partir das representaçóes sociais, que o conteúdo de saúde bucal seja incluído no currículo das escolas e que as açôes de promoção em saúde sejam prioritárias nos serviços de saúde. Mediante ao exposto, acredita-se que medidas significativas para a promoção da saúde e para a prevenção de doenças, no que diz respeito à facilitação do discernimento do indivíduo num contexto geral da vida, devem ser tomadas.

Educar em saúde bucal, mediante a constatação das necessidades da comunidade, por meio de levantamento em escolas, creches, associaçóes de bairros e outras entidades assistenciais, é de extrema necessidade. Devem ser adotadas estratégias que para minimização dos problemas, açôes preventivas e de promoção da saúde, como:

- palestras educativas, para as diversas faixas etárias, bem como para gestantes e portadores de necessidades especiais,

- elaboração e distribuição de folder,

- oficinas práticas de escovação (escovódromo),

- distribuição de kit de escovação e

- Aplicação tópica de flúor em escolas

\section{CONCLUSÃO}

Nos meios de comunicação, muito se fala em de que estamos na "era da comunicação", sem dúvida a comunicação teve nos últimos anos uma evolução considerável nos últimos anos, haja vista, recentemente as transmissóes em alta definição (HD). Dois aspectos são de suma importância considerar: a mídia está focada em interesses financeiros, não interessando para ela os projetos que não vão "engordar" as contas bancárias de seus acionistas e a mídia não chega em todos os pontos deste imenso país, talvez esteja aí a população mais necessitada, que provavelmente não conhece o processo mais rudimentar de higiene oral.

Os programas de educação em odontologia devem considerar os aspectos relativos ao conhecimento e as práticas em saúde bucal, a fim de viabilizar o processo de capacitação da populaçáo e promover a responsabilização coletiva e a promoção da saúde em todos os níveis da sociedade.

Existe a necessidade de criar grupos de ensino informal sobre os cuidados básicos com a higiene bucal, onde se contemple a presença do dentista, do técnico em saúde bucal, bem como de auxiliares em serviços odontológicos, a fim de levar nas escolas, postos de saúde, associação de moradores e em outras instituições que congreguem grupos de pessoas, em especial nas empresas, preferencialmente durante a jornada de trabalho, nos intervalos destinados ao descanso, garantindo assim a participação efetiva dos empregados.

Acreditamos que o papel de educar náo deve ser atribuição exclusiva do profissional convencionalmente deno- 
minado professor, mas de qualquer cidadáo, pois a todo o momento estamos educando e sendo educados através dos nossos contactos com outros seres humanos e com o meio ambiente. $\mathrm{O}$ cirurgião-dentista não foge a esta regra, razão pela qual consideramos útil o conteúdo deste trabalho.

Não podemos desmerecer o brilhaste trabalho desenvolvido pelas equipes de Estratégias em Saúde da Família (ESF), mas não podemos esquecer que este serviço náo cobre a totalidade da população brasileira. Portanto medidas educativas sobre a saúde bucal precisam ser tomadas, levando a toda a população, em especial a menos favorecida, através de palestras e medidas práticas (ensino informal) os conhecimentos básicos para uma higiene bucal, contribuindo assim para a saúde e consequentemente a qualidade de vida.

\section{BIBLIOGRAFIA}

ABEGG, C., Hábitos de Higiene Bucal de Adultos Portoalegrenses. Rev. Saúde Pública, São Paulo, v. 31, n. 6. p 586-593, dez. 1997.

ABREU, A. S., A arte de argumentar - Gerenciando razão e emoção. Cotia, Ateliê Editorial, 2006.

BALDANI, M.H. et al., Cárie dentária e Condiçóes sócioeconômicas no Estado do Paraná, 1996. Cad. Saúde Pública, Rio de Janeiro, 18 (3):755-763, set - out, 2002.

CARVALHO, M.B. et al., Características Clínico-Epidemiológicas do Carcinoma Epidemóide da Cavidade Oralno Sexo Feminino. Rev. da Associaçáo Médica Brasileira, São Paulo, vol.47, no. 3, p.208-214, July/Sept. 2001.

CHAVES, M.M., Odontologia Social. 3 ed. São Paulo: Artes Médicas, 1986.

COLUSSI, C.F., FREITAS, S.F.T., Aspectos Epidemiológicos da Saúde Bucal do Idoso no Brasil. Cad. Saúde Pública, Rio de Janeiro, 18 (5):1313-1320, set - out, 2002.

MATOS, I.B., ARAÚJO, L.A., Práticas Acadëmicas, Cirurgiôes-dentistas, População e Câncer Bucal. Rev. ABENO, Brasília, 3 (1):76-81, 2003.

McDONALD, R.E., AVERY, D.R., Odontopediatria. 7 ed. Rio de Janeiro: Guanabara Koogan S.A., 2000.

MONENEGRO, F.L.B., et al., A importância do bom funcionamento do sistema mastigatório para o processo digestivo do idosos. Rev. Kairós, 10 (2):245-257, 2007.
PAUlETO, A.R.C., PEREIRA, M.L.T., CYRINO, E.G., Saúde Bucal: Uma revisão Crítica sobre Programaçóes Educativas para Escolares. Ciênc. Saúde Coletiva, Rio de Janeiro, vol. 9, no 1, p.121-130, 2004.

PESSANHA, R.V., CUNHA, F.T.S., A Aprendizagem Trabalho e as Tecnologias de Saúde na Estratégia Saúde da Família. Texto contexto - Enferm. [online] 2009, vol. 18, no 2, p. 233-240. ISSN 0104-0707, Doi: 10.1590/S010407072009000200005 .

PINHEIRO, S.M.S., CARDOSO, J.P., PRADO, F.O., Conhecimentos e Diagnóstico em Câncer Bucal entre Profissionais de Odontologia de Jequié, Bahia. Rev. Brasileira de Cancerologia, 56 (2), p.195-205, 2010.

PINTO, V.G., Saúde Bucal Coletiva. 4 ed. São Paulo: Santos, 2000.

ROCHA, R. A. C. P., GOES, P. S. A., Comparação do acesso aos serviços de saúde bucal em áreas cobertas e não cobertas pela Estratégia de Saúde da Família em Campina Grande, Paraíba, Brasil. Cad. Saúde Pública, Rio de Janeiro, vol. 24, vol. 12, Dez. 2008.

ROSA, A. G. F. et al., Condiçóes de saúde bucal em pessoas de 60 anos ou mais no Município de São Paulo (Brasil). Rev. Saúde Pública, São Paulo, 26: 155-60, 1992.

SANTOS, L.C.O., et al., Câncer bucal: amostra populacional do estado. Rev. Brasileira de Otorrinolaringologia, São Paulo, 75 (4): Jul-Ago 2009.

UNFER, B., SALIBA, O., Avaliação do Conhecimento Popular e Práticas em Saúde Bucal. Rev. Saúde Pública, São Paulo, vol. 34, no. 2, Apr. 2000.

VAZ, A. C. R. Programas açôes educativas complementares. Anais do VIII Encontro de Extensáo da UFMG. Belo Horizonte, 2005.

Endereço para Correspondência:

Jair Antonio de Carvalho carvalho@superonda.com.br

Centro Universitário de Volta Redonda Campus Três Poços Av. Paulo Erlei Alves Abrantes, no 1325 , Três Poços - Volta Redonda / RJ CEP: 27240-560 